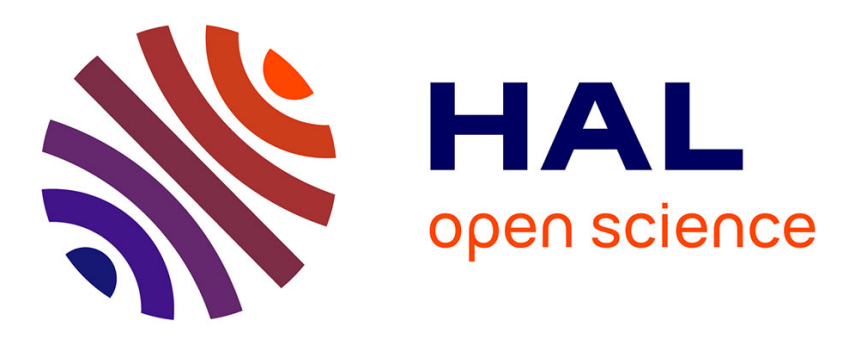

\title{
Tributyltin Hydride in NMP-Promoted Reduction of Acid Chlorides to Aldehydes under Transition-Metal-Free Conditions
}

Patrick Le Menez, Abdallah Hamze, Olivier Provot, Jean-Daniel Brion, Mouad Alami

\section{To cite this version:}

Patrick Le Menez, Abdallah Hamze, Olivier Provot, Jean-Daniel Brion, Mouad Alami. Tributyltin Hydride in NMP-Promoted Reduction of Acid Chlorides to Aldehydes under Transition-Metal-Free Conditions. SYNLETT, 2010, 2010 (07), pp.1101-1103. 10.1055/s-0029-1219796 . hal-02394579

\section{HAL Id: hal-02394579 \\ https://hal.science/hal-02394579}

Submitted on 4 Dec 2019

HAL is a multi-disciplinary open access archive for the deposit and dissemination of scientific research documents, whether they are published or not. The documents may come from teaching and research institutions in France or abroad, or from public or private research centers.
L'archive ouverte pluridisciplinaire HAL, est destinée au dépôt et à la diffusion de documents scientifiques de niveau recherche, publiés ou non, émanant des établissements d'enseignement et de recherche français ou étrangers, des laboratoires publics ou privés. 


\title{
$\mathrm{Bu}_{3} \mathrm{SnH}$ in NMP Promoted Reduction of Acid Chlorides to Aldehydes under Metal-Free Conditions
}

\author{
Patrick Le Ménez, Abdallah Hamze*, Olivier Provot, Jean-Daniel Brion and Mouâd Alami* \\ Univ Paris-Sud, CNRS, BioCIS UMR 8076, Laboratoire de Chimie Thérapeutique, Faculté de Pharmacie, 5 rue J.-B. Clément,
}

Châtenay-Malabry, F-92296, France.

Fax: +33-1-46.83.58.28;

E-mail: mouad.alami@u-psud.fr and/or abdallah.hamze@u-psud.fr

Received: The date will be inserted once the manuscript is accepted.

\begin{abstract}
Tributyltin hydride in NMP was used for the partial reduction of various functionalized acid chlorides at room temperature. This metal-free procedure allowed the synthesis of a range of (hetero)aromatic- and aliphatic aldehydes in good to excellent yields.
\end{abstract}

Key words: acid chlorides, aldehydes, reduction, tributyltin hydride, N-methylpyrrolidinone, free-metal conditions.

The partial reduction of acid chlorides to aldehydes seems to be a simple reaction, yet this type of transformation remains a desirable tool. Over the past decades, a variety of methods have been developed. Besides the traditionally hydrogenolysis with $\mathrm{Pd} / \mathrm{BaSO}_{4}$ (Rosenmund reduction), ${ }_{1}^{1}$ many metallic hydrides have been extensively used for such transformations, including, lithium or sodium tri-t-butoxyaluminium hydride, ${ }^{2}$ sodium borohydride, ${ }^{3}$ hypervalent silicon hydrides, ${ }^{4}$ transition metal borohydrides, ${ }^{5}$ anionic transition metal reductants, ${ }^{6}$ etc. ${ }^{7}$ However, the abovementioned methods are not exempt from some limitations which include over reduction, lack of generality, low yielding, functional groups compatibility. Alternative methods consist on using organosilicon ${ }^{8}$ or tributyltin hydrides ${ }^{9}$ in the presence of a transition metal catalyst. Since the pioneer work of Guibé, tributyltin hydride ${ }^{9 a, 10}$ reduction of acid chlorides to aldehydes in the presence of palladium catalyst holds certain supremacy and this procedure has been successfully applied to the synthesis of complex molecules. ${ }^{11}$

As part of our research program on the hydrostannation of arylalkynes ${ }^{12}$ and enynes, ${ }^{13}$ we have noticed the crucial influence of the solvent, particularly with NMP where a partial addition of tributyltin hydride across the carbon-carbon triple bond occurred in the absence of palladium catalyst. These findings have prompted us to investigate the particular reactivity of the $\mathrm{Bu}_{3} \mathrm{SnH} / \mathrm{NMP}$ system toward other functionalities such as the partial reduction of acid chlorides under metal free conditions. Herein we wish to report on our successful results.

First, we have studied the reduction of 4methoxybenzoyl chloride 1a as a model substrate. The results, summarized in Table 1 showed that treatment of $\mathbf{1 a}$ with $\mathrm{Bu}_{3} \mathrm{SnH}$ (1.1 equiv.) in THF was ineffective and only trace amount of over-reduced $\mathbf{3 a}$ was detected (entry 1). For comparison, with additional tetrakis(triphenylphosphine)palladium(0) (5 mol\%), $\mathrm{Bu}_{3} \mathrm{SnH}$ in THF was found to affect the reduction of 1a, furnishing 4-methoxybenzaldehyde 2a in $72 \%$ yield along with a small amount of benzyl alcohol 3a $(<5 \%$; data not shown). When the reaction was carried out without transition metal catalyst in $N, N$ dimethylacetamide (DMA) or $N, N^{\prime}$-dimethyl propyleneurea (DMPU) as solvents, the conversion rise to $\sim 50 \%$, but a noticeable amount of over-reduced 3a was detected in the crude reaction mixture (entries 2 and 3). Finally, when performing the reaction in NMP as a solvent, we were pleased to observe that the reduction of $\mathbf{1 a}$ with $\mathrm{Bu}_{3} \mathrm{SnH}$ (1.05 equiv.) at room temperature for $1 \mathrm{~h}$ proved to be successful furnishing the desired 4-methoxybenzaldehyde 2a in $81 \%$ yield (entry 5). Only trace amount of over reduced by-product 3a was detected.

Table 1 Effect of solvents on the reduction of 4-methoxybenzoyl chloride $\mathbf{1 a}$ to aldehyde $\mathbf{2 a}$ with $\mathrm{Bu}_{3} \mathrm{SnH}$ under metal free conditions.

\begin{tabular}{llllll}
\hline & & & & & \\
\hline
\end{tabular}

${ }^{a}$ Reaction was performed using 1.1 equiv of $\mathrm{HSnBu}_{3}$ at room temperature under argon for 1 to $2 \mathrm{~h}$. ${ }^{1} \mathrm{H}$ NMR ratio determined on the crude product.

b 2a was isolated in a $81 \%$ yield after column chromatography.

Increasing the reaction time, the temperature or the amount of $\mathrm{Bu}_{3} \mathrm{SnH}$ led to a decline in yield of the aldehyde 2a with an increasing formation of the overreduced by-product 3a (entries 6-8). In our system, it appeared that the use of NMP heightened the reactivity of the tributyltin hydride to where the acid chloride 1a can be converted to the aldehyde 2a without the need of a palladium catalyst. 
With optimized conditions in hand, ${ }^{14}$ our investigation shifted to an exploration of reaction scope. Several commercially available acid chlorides were reacted with the $\mathrm{Bu}_{3} \mathrm{SnH} / \mathrm{NMP}$ system at room temperature, as shown in Table 2.

The partial reduction of acid chlorides 1a-o with $\mathrm{Bu}_{3} \mathrm{SnH}$ in NMP leads to aldehydes 2a-o in good yields, without exception, demonstrating a broad reaction scope and tolerance of functional groups. Aromatic acid chlorides 1a-f bearing an electron-donating group were successfully transformed into their corresponding aldehyde derivatives $\mathbf{2 a - f}$ in good to excellent yields (entries 1-6). It should be noted that the position of the substituent on the aromatic ring had no influence with respect to yield and selectivity. An important aspect of this metal-free procedure is the survival of an $O$-allyl protecting group during the $\mathrm{Bu}_{3} \mathrm{SnH}$ partial reduction (entry 6). One can note that such transformation could not be selectively realized under the Guibé's protocol $\left(\mathrm{Bu}_{3} \mathrm{SnH} / \mathrm{Pd}\left(\mathrm{PPh}_{3}\right)_{4} / \mathrm{THF}\right)$ as these conditions are well-known to allow cleavage of an $O$-allylether function. ${ }^{15}$ As shown in entries 8 to 10 , the presence of an electron-withdrawing group on the aryl ring also did not affect the yield of the reduction and provided aldehydes $\mathbf{2} \mathbf{h}$-j $\mathbf{j}$ in good yields. It is particularly notable that a $\mathrm{NO}_{2}$ reducible substituent tolerated the reaction conditions ( $74 \%$, entry 9$)$. The reduction of other aromatic and heteroaromatic systems such as 1-naphtyl acid chloride 1k or 2-thienyl acid chloride 11 by $\mathrm{Bu}_{3} \mathrm{SnH}$ in NMP worked equally well, to give $\mathbf{2 k}$ and $\mathbf{2 l}$ in $90 \%$ and $93 \%$ yield, respectively (entries 11 and 12). $\alpha, \beta$-Unsaturated acid chloride $1 \mathbf{m}$ (entry 13 ) reacted well with 1.05 equiv. of tributyltin hydride in NMP to give the $\alpha, \beta$-unsaturated aldehyde $\mathbf{2 m}$ in a good $85 \%$ yield with no trace of the saturated aldehyde. Since few methods could achieve complete efficiency both to aromatic and aliphatic acid chlorides, it became essential to test the partial reduction of aliphatic substrates. Thus, as shown in entry 14 the $\mathrm{Bu}_{3} \mathrm{SnH} / \mathrm{NMP}$ protocol was optimal for the conversion of aliphatic acid chloride $\mathbf{1 n}$ to aldehyde $\mathbf{2 n}$, demonstrating the general character of the method. Finally, the reduction of citronelloyl chloride 1o (entry 15), gave only citronellal 2o, while reduction of $\mathbf{1 0}$ in the presence of azobis(isobutyronitrile) (AIBN) has been reported to give the cyclic compound menthone. ${ }^{16}$ This observation leads us to exclude a radical mechanism for the $\mathrm{Bu}_{3} \mathrm{SnH} / \mathrm{NMP}$ mediated reduction of acid chlorides.

In summary, we have developed a simple, efficient and general process for the partial reduction of acid chlorides using tributyltin hydride in NMP at room temperature. This mild and metal-free procedure works well with (hetero)aromatic as well as aliphatic acid chlorides and allows efficiently the preparation of a variety of functionalized aldehydes in good to excellent yields. In the present method, the survival of an $O$-allylether function, usually used as alcoholprotecting group, must be underlined as it constitutes a
Table 2 Scope of the reduction of acid chloride by $\mathrm{HSnBu}_{3} / \mathrm{NMP}$ system Reduction of acid chlorides to aldehydes with $\mathrm{Bu}_{3} \mathrm{SnH} / \mathrm{NMP}$ at room temperature: Scope of the reaction.
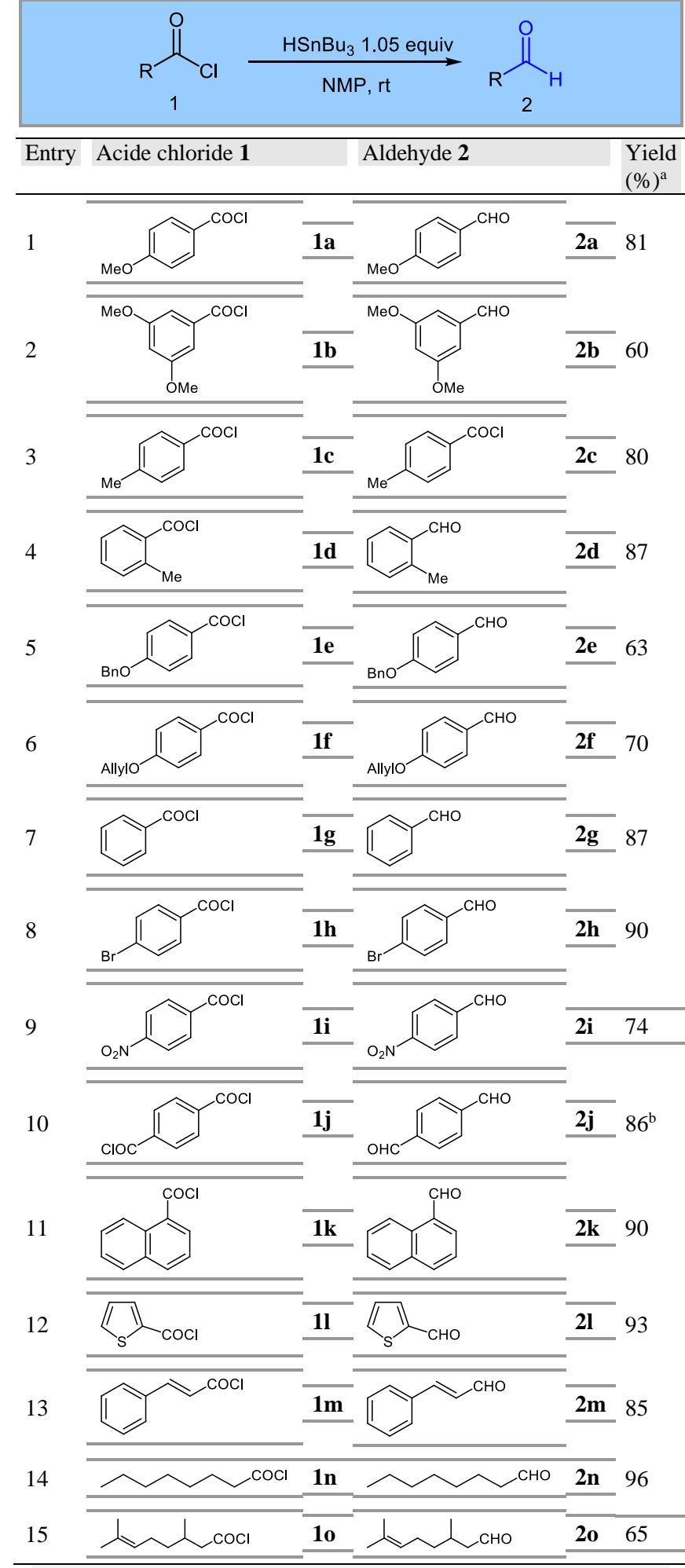

${ }^{a}$ Isolated yield Yields refer to isolated pure product after column chromatography

b 2.1 equiv. of $\mathrm{Bu}_{3} \mathrm{SnH}$ were used.

real advantage when compared with the previous palladium-catalyzed procedures. Due to its simplicity and versatility, we believe that this methodology should find broad applications in synthetic organic chemistry. 


\section{Acknowledgment}

The CNRS is gratefully thanked for support of this research.

\section{References}

(1) For reviews on the Rosenmund reduction, see: (a) Mosettig, E.; Mozingo, R. Org. React. 1948, 4, 362. (b) Larsen, R. D.; King, A. O. In Handbook of Organopalladium Chemistry for Organic Synthesis, Vol. 2, Negishi, E., Ed.; John Wiley and Soons: New York, 2002, Chap. VI. 2.4, 2473.

(2) (a) Brown, H. C.; McFarlin, R. F. J. Am. Chem. Soc. 1956, 78, 252. (b) Brown, H .C.; Subba Rao, B. C. J. Am. Chem. Soc. 1958, 80, 5377. (c) Brown, H. C.; Krishnamurthy, S. Tetrahedron 1979, 35, 567. (d) Cha, J. S.; Brown, H. C. J. Org. Chem. 1993, 58, 4732.

(3) Babler, J. H.; Invergo, B. J. Tetrahedron Lett. 1981, 22, 11.

(4) Corriu, R. J. P.; Lanneau, G. F.; Parrott, M. Tetrahedron Lett. 1988, 29, 1271.

(5) (a) Sorrell, T. N.; Spillane, R. J. Tetrahedron Lett. 1978, 19, 2473. (b) Fleet, G. W. J.; Fuller, C. J.; Harding, P. J. C. Tetrahedron Lett. 1978, 19, 1437. (c) Fleet, G. W. J.; Harding, P. J. C. Tetrahedron Lett. 1978, 19, 975. (d) Sorrell, T. N.; Pearlman, P. S. J. Org. Chem. 1980, 45, 3449. (e) Hutchins, R. O.; Markowitz, M. Tetrahedron Lett. 1980, 21, 813. (f) Johnstone, R. A. W.; Telford, R. P. Chem. Commun. 1978, 354.

(6) (a) Cooke, M. P. J. Am. Chem. Soc. 1970, 92, 6080. (b) Watanabe,Y; Mitaudo, T.; Tanaka, M.; Yamamoto, K.; Okajima, T.; Takegami, Y. Bull. Chem. Soc. Jpn. 1971, 44, 2569. (c) Siegl, W. O.; Collman, J. P. J. Am. Chem. Soc. 1972, 94, 2516. (d) Cole, T. E.; Pettit, R. Tetrahedron Lett. 1977, 18, 781. (e) Kinney, R. J.; Jones, W. D.; Bergman, R. J. Am. Chem. Soc. 1978, 100, 7902. (f) Kao, S. C.; Gaua, P. L.; Youngdahl, K.; Darenabourg, M. Y. Organometallics 1984, 3, 1601.

(7) (a) Shamsuddin, K. M.; Zobairi, M. O.; Musharraf, M. A. Tetrahedron Lett. 1998, 39, 8153. (b) Jia, X.; Liu, X.; Li, J.; Zhao, P.; Zhang, Y. Tetrahedron Lett. 2007, 48, 971. (c) Maeda, H.; Maki, T.; Ohmori, H. Tetrahedron Lett. 1995, 36, 2247.

(8) (a) Citron, J. D. J. Org. Chem. 1969, 34, 1977. (b) Courtis, B.; Dent, S. P.; Eaborn, C.; Pidcock, A. J. Chem. Soc. Dalton Trans. 1975, 2460. (c) Lee, K.L.; Maleczka, Jr, R. E. Org. Lett. 2006, 8, 1887.

(9) (a) Guibé, F.; Four, P.; Rivière, H. J. Chem. Soc. Chem. Commun. 1980, 432. (b) Four, P.; Guibé F. J. Org. Chem. 1981, 46, 4439. (c) Malanga, C.; Mannucci, S.; Lardicci, L. Tetrahedron Lett. 1997, 38, 8093. (d) Inoue, K.; Yasuda, M.; Shibata, I.; Baba, A. Tetrahedron Lett. 2000, 41, 113.

(10)For reviews; see: (a) Neumann, W. P. Synthesis 1987, 665. (b) Mitchell, T. N. J. Organomet. Chem. 1986, 304, 1.

(11)(a) Stern, E.; Muccioli, G. G.; Bosier, B.; Hamtiaux, L.; Millet, R.; Poupaert, J. H.; Henichart, J. P.; Depreux, P.; Goossens, J. F.; Lambert, D. M. J. Med. Chem. 2007, 50, 5471. (b) Chelliah, M. V.; Chackalamannil, S.; Xia, Y.; Eagen, K.; Clasby, M. C.; Gao, X. B.; Greenlee, W.; Ahn, H. S.; Agans-Fantuzzi, J.; Boykow, G.; Hsieh, Y. S.; Bryant, M.; Palamanda, J.; Chan, T. M.; Hesk, D.; Chintala, M. J. Med. Chem. 2007, 50, 5147. (c) Gracia, J.; Thomas, E. J. J. Chem. Soc. Perkin Trans. 1, 1998, 17, 2865. (12)(a) Liron, F.; Le Garrec P.; Alami, M. Synlett 1999, 246. (b) Alami, M.; Liron, F.; Gervais, M.; Peyrat, J.-F.; Brion, J.D. Angew. Chem. Int. Ed. 2002, 41, 1578. (c) Liron, F.; Gervais, M.; Peyrat, J.-F.; Alami, M.; Brion, J.-D. Tetrahedron Lett. 2003, 44, 2789. (d) Hamze, A.; Provot, O.; Alami, M.; Brion, J.-D. Org. Lett. 2005, 7, 5625.

(13)(a) Alami, M.; Ferri, F. Synlett 1996, 755. (b) Ferri, F.; Alami, M. Tetrahedron Lett. 1996, 37, 7971. (c) Ferri, F.; Alami, M. Tetrahedron Lett. 1998, 39, 4243. (d) Hamze, A.; Provot, O.; Brion, J.-D.; Alami, M. J. Org. Chem. 2007, 72, 3868. (e) Hamze, A.; Veau, D.; Provot, O.; Brion, J.-D.; Alami, M. J. Org. Chem. 2009, 74, 1337.

(14)Typical procedure: Acid chloride 1 (1 mmol) was dissolved in NMP (1 mL) under an argon atmosphere. Bu3SnH (1.05 mmol) was next added dropwise and the resulting mixture was stirred for $1 \mathrm{~h}$ at room temperature. Then, $\mathrm{H}_{2} \mathrm{O}(2 \mathrm{~mL})$ was added and the mixture was extracted with EtOAc $(3 \mathrm{x}$ $5 \mathrm{~mL}$ ). Combined organic phase were washed with an aqueous saturated $\mathrm{NH}_{4} \mathrm{Cl}$ solution $(3 \times 5 \mathrm{~mL})$, dried over $\mathrm{MgSO}_{4}$ and concentrated. The crude mixture was then purified by column chromatography on silica gel to give the desired aldehyde compound 2.

(15)(a) Guibe, F.; Dangles, O.; Balavoine, G. Tetrahedron Lett. 1986, 27, 2365. (b) L'Hermite, N.; Peyrat, J.-F.; Hildgen, P.; Brion, J.-D.; Alami, M. Synthesis 2008, 1049.

(16)Cekovic, Z. Tetrahedron Lett. 1972, 13, 749. 